\title{
ANALISIS KUALITAS PELAYANAN AKADEMIK DENGAN METODE SERVPERF DAN IPA
}

\author{
Rizky Oktaviani Putri, Shantika Martha
}

\begin{abstract}
INTISARI
Service Performance (SERVPERF) merupakan metode pengembangan dari Service Quality (SERVQUAL). SERVPERF menggunakan skala kinerja dan skala kepentingan untuk mengukur kualitas jasa, sedangkan Important Performance Analysis merupakan metode yang memiliki kemampuan untuk mengidentifikasi prioritas yang diperlukan untuk perbaikan. Penelitian ini bertujuan untuk menganalisis kualitas pelayanan akademik FMIPA Untan pada mahasiswa tahun 2017/2018. Data dalam penelitian ini menggunakan data primer yang diperoleh melalui penyebaran kuesioner kepada responden yang telah ditentukan. Hasil penelitian menunjukkan bahwa ada beberapa atribut yang memerlukan perbaikan seperti kemudahan memperoleh informasi bagi mahasiswa (t3), proses pelayanan cepat dan tidak berbelit terkait dengan kebutuhan mahasiswa (r2), kesabaran petugas dalam menanggapi keluhan mahasiswa (e1).
\end{abstract}

Kata Kunci: Kualitas Pelayanan, SERVPERF, IPA

\section{PENDAHULUAN}

Pelayanan akademik pada Fakultas Matematika dan Ilmu Pengetahuan Alam, Universitas Tanjungpura (FMIPA UNTAN) dilaksanakan oleh Subbagian Akademik dan Kemahasiswaan. Subbagian Akademik dan Kemahasiswaan memiliki tugas pendukung di dalam aktivitas pengajaran dan administrasi seperti dalam bentuk lembar rencana studi (LIRS), lembar isi hasil studi (LIHS), informasi beasiswa, jadwal kuliah dan pengelolaan administrasi lainnya. Banyaknya tugas pelayanan yang dilakukan pada Subbagian Akademik dan Kemahasiswaan ini membuat petugas pelayanan lebih banyak berinteraksi dengan mahasiswa secara langsung. Meningkatkan kinerja dalam memberi pelayanan sangatlah penting untuk meningkatkan kualitas pelayanan yang ada. Oleh karena itu tanggapan mahasiswa sebagai konsumen dalam menerima pelayanan tentunya sangat diperlukan untuk memajukan mutu pelayanan. Kepuasan konsumen dalam menerima pelayanan adalah hak yang harus diterima setiap konsumen yang merasakannya. Dalam meningkatkan kualitas pelayanan, evaluasi perlu dilakukan untuk mengukur kualitas pelayanan tersebut.

Salah satu metode yang digunakan dalam pengukuran kualitas pelayanan jasa adalah Service Performance (SERVPERF) dan Important Performance Analysis (IPA). SERVPERF adalah kinerja dari pelayanan yang diterima oleh konsumen itu sendiri dan menilai kualitas pelayanan yang benarbenar mereka rasakan. SERVPERF memiliki keunggulan dalam memberi informasi atribut kualitas pelayanan mana yang penting untuk diperbaiki [1]. Pengukuran didalam SERVPERF berdasarkan dari kinerja proses pelayanannya. IPA merupakan alat bantu yang digunakan untuk membandingkan sampai sejauh mana antara kinerja yang dirasakan dibanding dengan tingkat kepuasan yang diinginkan. Pada penelitian ini, metode SERVPERF dan IPA digunakan untuk mengukur kualitas

pelayanan jasa pada bagian akademik di FMIPA. Evaluasi untuk mengukur kualitas pelayanan akademik ini terbagi dalam lima dimensi yaitu tangible (bukti fisik atau nyata), reliability (kehandalan), responsiveness (daya tanggap), assurance (jaminan) dan empathy (perhatian). 


\section{KUALITAS PELAYANAN}

Pada dasarnya kualitas terdiri dari sejumlah keistimewaan produk yang dapat memenuhi keinginan pelanggan dan memberikan kepuasan. Kualitas juga terdiri dari segala sesuatu yang bebas dari kekurangan atau kerusakan. Kualitas biasanya menggambarkan karakteristik langsung dari suatu produk seperti kinerja, kehandalan, mudah dalam penggunaan, dan estetika [2] Pelayanan adalah upaya pemuasan terhadap konsumen yang merupakan kewajiban yang harus ditingkatkan. Pelayanan dapat diartikan sebagai aktivitas yang diberikan untuk membantu, menyiapkan dan mengurus baik itu berupa barang atau jasa dari satu pihak ke pihak lain [3]. Pengukuran kinerja pelayanan dapat dilakukan dengan menggunakan lima dimensi kualitas pelayanan yaitu sebagai berikut:

1. Tangibles (bukti fisik atau nyata)

Dimensi ini merupakan penampakan fisik dari gedung, peralatan, pegawai dan fasilitas-fasilitas lain serta sarana komunikasi karena jasa tidak dapat diamati secara langsung.

2. Reliability (kehandalan)

Dimensi yang meliputi kemampuan untuk menghasilkan kinerja pelayanan yang dijanjikan secara akurat dan pasti, oleh karena itu pelayanan harus tepat waktu dan memberikan pelayanan yang sama untuk semua konsumen dan tanpa kesalahan kapanpun pelayanan diberikan.

3. Responsiveness (daya tanggap)

Dimensi yang meliputi tentang kemauan untuk menolong konsumen dan menyelenggarakan pelayanan secara ikhlas tanpa adanya paksaan serta memberikan pelayanan yang cepat. Jika pemberi pelayanan membiarkan konsumen menunggu tanpa ada alasan yang jelas maka akan menyebabkan kinerja yang tidak baik dalam pelayanan.

4. Assurance (jaminan)

Dimensi yang meliputi tentang pengetahuan pemberi pelayanan, kesopanan para pemberi pelayanan dan kemampuan mereka dalam memberikan jaminan keamanan terhadap konsumen agar timbul rasa kepercayaan konsumen terhadap pemberi pelayanan.

5. Empathy (perhatian)

Dimensi yang menjelaskan penjiwaan dan perhatian secara pribadi terhadap konsumen serta adanya kemudahan dalam melakukan hubungan komunikasi yang baik dan juga pemahaman atas kebutuhan konsumen.

\section{UJI VALIDITAS}

Uji validitas merupakan uji yang digunakan untuk menunjukkan sejauh mana ketepatan alat ukur mampu mengukur apa yang ingin diukur. Pengambilan keputusan pada uji validitas dengan hipotesis:

$H_{0}$ : Pertanyaan kuesioner valid

$H_{1}$ : Pertanyaan kuesioner tidak valid

Persamaan uji validitas pertanyaan ke-j dapat dinyatakan sebagai berikut [4]:

$$
r_{j}=\frac{n \sum_{i=1}^{n} X_{i j} Y_{i}-\left(\sum_{i=1}^{n} X_{i j}\right)\left(\sum_{i=1}^{n} Y_{i}\right)}{\sqrt{\left(n \sum_{i=1}^{n} X_{i j}{ }^{2}-\left(\sum_{i=1}^{n} X_{i j}\right)^{2}\right)\left(n \sum_{i=1}^{n} Y_{i}{ }^{2}-\left(\sum_{i=1}^{n} Y_{i}\right)^{2}\right)}}
$$

dimana $X_{i j}$ adalah skor pertanyaan ke- $j$ dengan $j=1,2,3, \ldots, k$ dari responden ke- $i$ dengan $i=1,2,3, \ldots, n$ dan $Y_{i}$ adalah skor total jawaban responden. Dengan $k$ adalah jumlah pertanyaan dan $n$ adalah jumlah 
responden. Dalam pengambilan keputusan, pertanyaan ke-j dinyatakan valid jika $r_{\text {hitung }} \geq$ $r_{\text {tabel }(\alpha, n-2)}$ maka $\mathrm{H}_{0}$ diterima.

\section{UJI RELIABILITAS}

Reliabilitas merupakan sejauh mana hasil dari suatu pengukuran dapat dipercaya. Skala pengukuran yang reliabel sebaiknya memiliki Cronbach Alpha $\geq 0,7$ [5]. Pengambilan keputusan pada uji reliabilitas dengan hipotesis:

$H_{0}$ : Dimensi kuesioner reliabel

$H_{1}$ : Dimensi kuesioner tidak reliabel

Persamaan uji reliabilitas dihitung dengan persamaan berikut [4]:

Menentukan nilai varian setiap butir pertanyaan:

$$
\sigma_{j}^{2}=\frac{\sum_{i=1}^{n} X_{i j}{ }^{2}-\frac{\left(\sum_{i=1}^{n} X_{i j}\right)^{2}}{n}}{n}
$$

dimana $\sigma_{j}^{2}$ adalah nilai varian setiap butir pertanyaan ke- $j, X_{i j}$ adalah skor pertanyaan ke-j dengan $j=1,2,3, \ldots, k$ dari responden ke- $i$ dengan $i=1,2,3, \ldots, n$ dan $n$ adalah jumlah responden.

Menentukan nilai varian total:

$$
\sigma_{i}^{2}=\frac{\sum_{i=1}^{n} Y_{i}{ }^{2}-\frac{\left(\sum_{i=1}^{n} Y_{i}\right)^{2}}{n}}{n}
$$

dimana $\sigma_{t}^{2}$ adalah nilai varian total, $Y_{i}$ adalah skor total jawaban responden dan $n$ adalah jumlah responden.

Menentukan reliabilitas kuesioner:

$$
r_{v}=\left[\frac{k_{v}}{k_{v}-1}\right]\left[1-\frac{\sum_{j=1}^{k_{v}} \sigma_{j}{ }^{2}}{\sigma_{t}^{2}}\right]
$$

dimana $v$ adalah dimensi $1,2, \ldots, 5$ dan $k_{v}$ adalah pertanyaan di dalam dimensi $1,2, \ldots, 5$.

Reliabilitas kuesioner dikriteriakan sebagai berikut:

1. $r_{v}<0,2 \quad$ : dimensi kuesioner tidak reliabel

2. $0,2 \leq r_{v}<0,4$ : reliabel dimensi kuesioner kecil

3. $0,4 \leq r_{v}<0,7$ : dimensi kuesioner cukup reliabel

4. $0,7 \leq r_{v}<0,9$ : dimensi kuesioner reliabel

5. $0,9 \leq r_{v}<1,0$ : dimensi kuesioner sangat reliabel

6. $r_{v}=1,0 \quad$ : reliabilitas dimensi kuesioner sempurna

Dalam pengambilan keputusan dimensi kuesioner tidak reliabel jika $r_{v}<0,2$ maka $H_{0}$ ditolak. 


\section{UKURAN SAMPEL}

Sampel adalah sebagian anggota populasi yang dapat mewakili populasi itu sendiri. Jumlah populasi yang banyak akan diambil untuk dijadikan sampel. Penentuan ukuran sampel dapat digunakan menggunakan rumus Slovin seperti berikut [4]:

$$
n=\frac{N}{1+N e^{2}}
$$

dimana $n$ adalah jumlah responden, $N$ adalah jumlah populasi dan $e$ adalah error.

\section{SERVPERF}

SERVPERF adalah suatu kinerja dari pelayanan yang diterima oleh konsumen dan menilai kualitas dari pelayanan yang benar-benar mereka rasakan [1]. Menurut Cronin dan Taylor (1992) skala SERVPERF adalah skala yang tepat untuk mengukur kualitas jasa karena tidak menggunakan perbandingan persepsi dan harapan untuk mengukur kualitas jasa melainkan menggunakan pengukuran kualitas jasa yang berdasarkan performance atau kinerja [6]. Skala kinerja dan Skala Kepentingan dari kualitas pelayanan dapat dihitung menggunakan persamaan [7]:

$$
S P_{j}=\sum_{i=1}^{n} P_{i j}, S Q_{j}=\sum_{i=1}^{n} Q_{i j}
$$

Dimana $S P_{j}$ merupakan angka tingkat kinerja atribut, $P_{i j}$ adalah skor kinerja, $S Q_{j}$ merupakan angka tingkat kepentingan atribut, dan $Q_{i j}$ adalah skor kepentingan.

\section{IPA}

IPA merupakan metode pengukuran kualitas pelayanan untuk mengetahui hubungan antara kinerja konsumen dengan prioritas peningkatan kualitas. Kelebihan dari metode IPA adalah kemampuannya untuk mengidentifikasi prioritas yang diperlukan untuk perbaikan. Tingkat kesesuaian merupakan hasil perbandingan antara skor kinerja dengan kepentingan [8]. Persamaan yang digunakan [9]:

dimana $\quad \bar{P}_{i j}=\frac{\sum_{i=1}^{n} P_{i j}}{n}, \bar{Q}_{i j}=\frac{\sum_{i=1}^{n} Q_{i j}}{n}$

dengan $T K_{j}$ adalah tingkat kesesuaian $\bar{P}_{i j}$ adalah rata-rata skor kinerja dan $\bar{Q}_{i j}$ adalah rata-rata skor kepentingan. Setiap variabel $i=1,2,3, \ldots, n$ dan $n$ merupakan jumlah responden. dimana $\bar{P}$ untuk sumbu horizontal, sedangkan $\bar{Q}$ untuk sumbu vertikal yang dibatasi oleh dua buah garis yang berpotongan pada titik-titik ( $\bar{P}, \bar{Q})$. Persamaan yang digunakan:

$$
\overline{\bar{P}}_{i j}=\frac{\sum_{i=1}^{n} \bar{P}_{i j}}{n}, \quad \overline{\bar{Q}}_{i j}=\frac{\sum_{i=1}^{n} \bar{Q}_{i j}}{n}
$$

dengan $\overline{\bar{P}}_{i j}$ adalah rata-rata dari rata-rata skor kinerja, $\overline{\bar{Q}}_{i j}$ adalah rata-rata dari rata-rata skor kepentingan. Penilaian skor kinerja maupun skor kepentingan dijabarkan ke dalam kuadran IPA. 


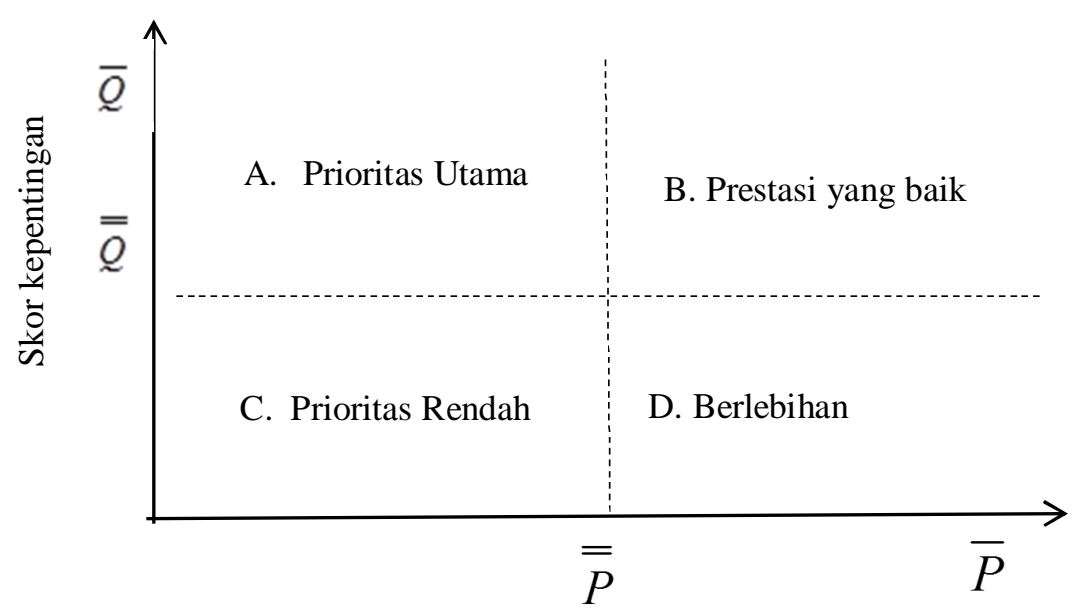

Skor kineria

Gambar 1 Kuadran IPA

Interpretasi untuk diagram kuadran IPA adalah Kuadran A yaitu atribut yang terletak pada posisi ini dianggap sebagai faktor yang kepentingan nya tinggi tetapi kinerja yang dilakukan rendah atau belum memuaskan bagi responden. Atribut yang terletak pada kuadran A merupakan prioritas yang harus ditingkatkan. Kuadran B yaitu atribut yang terletak pada posisi ini dianggap penting dan diharapkan sebagai faktor penunjang bagi kepuasan konsumen. Pada kuadran B responden mengharapkan agar pihak manajemen atau penyedia jasa mempunyai kewajiban untuk memastikan bahwa kinerja yang dihasilkan dapat mempertahankan prestasi yang telah dicapai. Kuadran $\mathrm{C}$ yaitu atribut yang terletak pada posisi ini kurang dianggap penting tetapi tingkat kepuasan konsumen cukup baik namun konsumen mengabaikan atribut yang terletak pada posisi ini sehingga pihak manajemen tidak perlu memprioritaskan tetapi pihak penyedia jasa boleh melakukan perbaikan atau peningkatan kerja. Kuadran D yaitu atribut yang terletak pada posisi ini dianggap kurang penting tetapi tingkat kepuasan dari konsumen sangat memuaskan atau bisa di bilang kinerja dari pegawai yang berlebihan.

\section{STUDI KASUS}

Data yang digunakan dalam penelitian ini adalah data primer. Data diperoleh dari penyebaran kuesioner kualitas pelayanan akademik FMIPA UNTAN kepada mahasiswa tahun ajaran 2017/2018 sebanyak 240 mahasiswa. Kuesioner terdiri dari 33 pernyataan dari lima dimensi. Masing-masing dari dimensi memiliki beberapa pernyataan seperti pada Tabel 1 berikut ini: 
Tabel 1 Pernyataan Kuesioner

\begin{tabular}{|c|c|c|}
\hline Dimensi & Pernyataan & Atribut \\
\hline \multirow{9}{*}{ Tangible } & kondisi kantor bersih, rapi dan nyaman & $\mathrm{t} 1$ \\
\hline & penampilan petugas rapi dan sopan & $\mathrm{t} 2$ \\
\hline & kemudahan memperoleh informasi bagi mahasiswa & $\mathrm{t} 3$ \\
\hline & profesionalisme sikap petugas dalam melayani mahasiswa & $\mathrm{t} 4$ \\
\hline & jumlah loket pelayanan yang memadai & $\mathrm{t} 5$ \\
\hline & adanya fasilitas ruang tunggu & t6 \\
\hline & adanya sarana komunikasi online & $\mathrm{t} 7$ \\
\hline & keramahan petugas dalam melayani mahasiswa & $\mathrm{t} 8$ \\
\hline & kesopanan sikap petugas yang ditunjukan & t9 \\
\hline \multirow{6}{*}{ Reliability } & disiplin waktu pelayanan (jam buka dan tutup) & r1 \\
\hline & proses pelayanan cepat dan tidak berbelit terkait dengan kebutuhan mahasiswa & $\mathrm{r} 2$ \\
\hline & petugas dapat menyelesaikan pekerjaan dengan cepat & r3 \\
\hline & petugas dapat menyelesaikan pekerjaan dengan akurat & $\mathrm{r} 4$ \\
\hline & kejelasan informasi yang diberikan petugas kepada mahasiswa & r5 \\
\hline & ketelitian petugas dalam memberikan pelayanan kepada mahasiswa & r6 \\
\hline \multirow{4}{*}{ Responsive } & ketanggapan petugas dalam merespon keluhan mahasiswa & re1 \\
\hline & petugas memperlihatkan antusiasme dalam bekerja & re2 \\
\hline & toleransi petugas ketika mahasiswa mengalami kesulitan & re3 \\
\hline & petugas lebih bertanggung jawab terhadap pekerjaanya & re4 \\
\hline \multirow{7}{*}{ Assurance } & petugas memiliki kredibilitas yang baik di mata mahasiswa & a1 \\
\hline & $\begin{array}{l}\text { rasa percaya mahasiswa dengan penyelesaian yang dijanjikan akan segera } \\
\text { dipenuhi }\end{array}$ & $\mathrm{a} 2$ \\
\hline & pengalaman kerja petugas & a3 \\
\hline & penguasaan kerja petugas & $\mathrm{a} 4$ \\
\hline & jaminan tidak ada kesalahan dalam menyelesaikan pekerjaan & a5 \\
\hline & petugas mampu menjawab pertanyaan & a6 \\
\hline & petugas memiliki pengetahuan yang luas & a7 \\
\hline \multirow{7}{*}{ Empathy } & kesabaran petugas dalam menanggapi keluhan mahasiswa & e1 \\
\hline & kesabaran petugas dalam memberikan pelayanan & e2 \\
\hline & ketulusan petugas dalam menangani mahasiswa & e3 \\
\hline & petugas menggunakan bahasa yang mudah dimengerti & e4 \\
\hline & petugas memahami kebutuhan spesifik mahasiswa & e5 \\
\hline & petugas memberikan solusi terhadap komplai mahasiswa & e6 \\
\hline & pelayanan terhadap mahasiswa tidak diskriminatif & $\mathrm{e} 7$ \\
\hline
\end{tabular}

Nilai tingkat kesesuaian untuk hasil skor kinerja dan skor kepentingan berada pada rentang nilai 79\% 92\% dengan rata-rata tingkat kesesuaian adalah $83 \%$. Rata-rata nilai skor kinerja dan rata-rata nilai skor kepentingan untuk setiap atribut kemudian diplotkan kedalam kuadran IPA, dapat dilihat pada Gambar 2. 


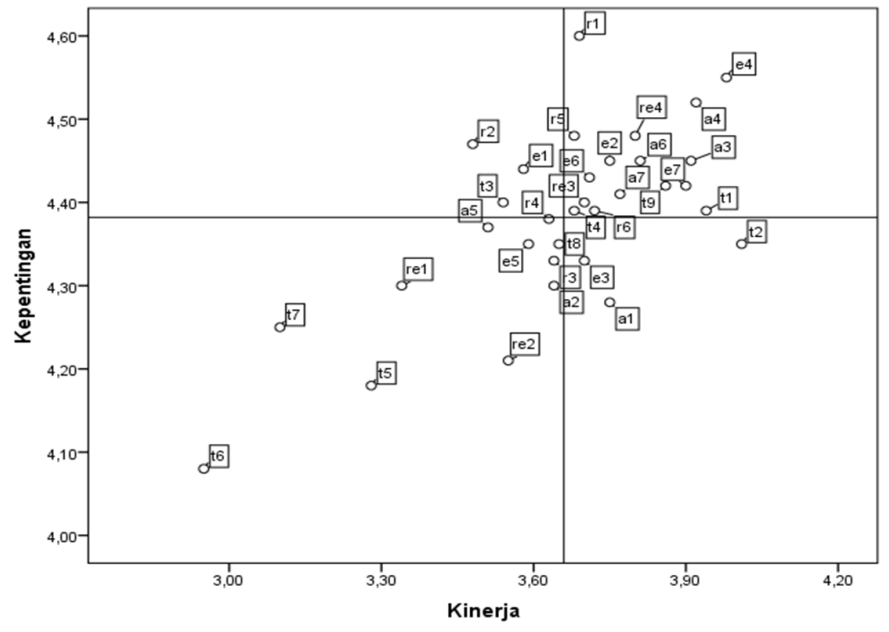

Gambar 2 Kuadran IPA

Berdasarkan hasil ploting tersebut untuk setiap atribut dapat dikelompokan kedalam masingmasing kuadran berikut ini:

1. Kuadran A menunjukan tingkat prioritas utama tetapi kinerja masih rendah. Atribut-atribut yang masuk didalam kuadran A ini adalah $\mathrm{t} 3, \mathrm{r} 2$ dan e1.

2. Kuadran B menunjukan atribut sudah baik dan perlu di pertahankan karena responden sudah merasa puas dengan hasil kinerja yang telah dilakukan karyawan. Atribut-atribut yang masuk didalam kuadran B ini adalah t1, t4, t9, r1, r5, r6, re3, re4, a3, a4, a6, a7, e2, e4, e6 dan e7.

3. Kuadran $\mathrm{C}$ menunjukan tingkat kinerja dan tingkat kepentingan rendah sehingga responden tidak terlalu mementingkan akan rendahnya kinerja karena bukan prioritas utama. Atributatribut yang masuk didalam kuadran $\mathrm{C}$ ini adalah $\mathrm{t} 5, \mathrm{t} 6, \mathrm{t} 7, \mathrm{t} 8, \mathrm{r} 3, \mathrm{r} 4$, re1,re2, a2, a5 dan e5

4. Kuadran D menunjukan tingkat kepentingan rendah namun tingkat kinerja yang cukup tinggi. Hal ini bisa dikatakan sebagai sesuatu yang berlebihan karena kurang memberikan nilai bagi responden. Atribut-atribut yang masuk didalam kuadran D ini adalah t2, a1 dan e3.

\section{PENUTUP dan SARAN}

Berdasarkan hasil penelitian yang telah dilakukan kepada mahasiswa tahun 2017/2018 dapat disimpulkan bahwa ada beberapa atribut yang perlu dilakukan perbaikan. Atribut yang perlu segera dilakukan perbaikan adalah kemudahan memperoleh informasi bagi mahasiswa ( $\mathrm{t} 3$ ), proses pelayanan cepat dan tidak berbelit terkait dengan kebutuhan mahasiswa (r2) dan kesabaran petugas dalam menanggapi keluhan mahasiswa (e1). Atribut yang perlu di tingkatkan kinerjanya walaupun bukan prioritas utama adalah jumlah loket pelayanan tang memadai (t5), fasilitas ruang tunggu (t6), sarana komunikasi online (t7), keramahan petugas dalam melayani mahasiswa (t8), petugas dapat menyelesaikan pekerjaan dengan cepat (r3), petugas dapat menyelesaikan dengan akurat (r4), ketanggapan petugas dalam merespon mahasiswa (re1), antusiasme dalam bekerja (re2), rasa percaya mahasiswa dengan penyelesaian yang dijanjikan akan terpenuhi (a2), jaminan tidak terjadi kesalahan dalam menyelesaikan pekerjaan (a5) dan memahami kebutuhan spesifik mahasiswa (e5).

Untuk memperbaiki kualitas pelayanan yang ada, sangat disarankan agar Subbagian Akademik dan Kemahasiswaan untuk lebih memperhatikan mahasiswa dalam memberikan pelayanan khusus nya dalam hal informasi terkait mahasiswa baik beasiswa, perkuliahan dan info lainnya. Memperhatikan proses pelayanan agar tidak berbelit dan dikemas menjadi lebih mudah. Selain itu kesabaran petugas diharapkan lebih ekstra dalam menanggapi keluhan dari mahasiswa. Subbagian Akademik dan 
Kemahasiswaan perlu mengadakan pendidikan dan pelatihan pada pegawai agar dapat memantau dan memperhatikan kualitas pelayanan yang baik bagi mahasiswa.

\section{DAFTAR PUSTAKA}

[1]. Dharmayanti, D. Analisis Dampak Service Performance dan Kepuasan Sebagai Moderating Variable Terhadap Loyalitas Nasabah, Manajemen Pemasaran; 2006; 1(1):35-43.

[2]. Sinambela, L.P. Reformasi Pelayanan Publik: Teori, Kebijakan, dan Implementasi. Jakarta: PT. Bumi Aksara; 2006.

[3]. Hardiansyah, J. Kualitas Pelayanan Publik Konsep, Dimensi, Indikator, dan Implementasinya. Yogyakarta: Gava Media; 2011.

[4]. Siregar, S. Statistik Parametik untuk Penelitian Kuantitatif. Jakarta: PT. Bumi Aksara; 2013.

[5]. Rosyidah, H., Wuryandari, T., dan Rusgiyono, A. Analisis Kualitas Pelayanan dengan Menggunakan Fuzzy SERVQUAL, Kuadran IPA, dan Indeks PGGV. Gaussian; 2015;4(4): 885-894.

[6]. Marbun, S., dan Suardika, I.N. Pengaruh Service Performance Terhadap Nilai Institusi dan Kepuasan Mahasiswa. Manajemen dan Akuntansi; 2013;19(1): 52-72.

[7]. Jain, S.K., dan Gupta, G. Measuring Service Quality: SERVQUAL vs. SERVPERF Scales. Vikalpa; 2014;29(2): 25-37.

[8]. Yola, M., dan Budianto, D. Analisis Kepuasan Konsumen Terhadap Kualitas Pelayanan dan Harga Produk Pada Supermarket dengan Menggunakan Metode Importance Performance Analysis (IPA). Optimasi Sistem Industri; 2013;12(12): 301-309.

[9]. Nugraha, R., Harsono, A., dan Adianto, H. Usulan Peningkatan Kualitas Pelayanan Jasa pada Bengkel "X” Berdasarkan Hasil Matrix Important-Performance Analysis. Itenas; 2014;3(1): 221-231.

$\begin{array}{ll}\text { RIZKY OKTAVIANI PUTRI } & \begin{array}{c}\text { : Jurusan Matematika FMIPA UNTAN, Pontianak } \\ \text { rizkyoktavianiputri@gmail.com }\end{array} \\ \text { SHANTIKA MARTHA } & \begin{array}{c}\text { : Jurusan Matematika FMIPA UNTAN, Pontianak } \\ \text { shantika.martha@ math.untan.ac.id }\end{array}\end{array}$

